Lelliott, P., Young, E. \& Burgess, R. (2009) A Core Model for Professionally Led Clinical Service Accreditation, Version 2:26TH. Available at http:// www.hqip.org.uk/assets/Core-model-for-clinical-service-accreditation. doc (accessed 3 August 2010).

McQueen, D., Ikkos, G., St John-Smith, P., et al (2010) Psychiatry's contract with society: what do clinical psychiatrists expect? In Psychiatry's Contract With Society (eds D. Bhugra, A. Malik \& G. Ikkos), ch. 8. Oxford University Press.
Panksepp, J. (2009) A non-reductive physicalist account of affective consciousness. In The Neuropsychology of Mental IIIness (eds S. Wood, N. B. Allen \& C. Pantelis), ch. 28. Cambridge University Press.

Stephens, G. L. \& Graham, G. (2009) Mental illness and the consciousness thesis. In The Neuropsychology of Mental Illness (eds S. Wood, N. B. Allen \& C. Pantelis), ch. 27. Cambridge University Press.

\title{
Alcohol misuse by the young: problems and solutions
}

\author{
David Skuse
}

Behavioural and Brain Sciences Unit, Institute of Child Health, London, UK, email dskuse@ich.ucl.ac.uk

$B_{0}^{a c t i n t}$ ack in April 2006 (vol. 3, no. 2) we published papers on the theme of misuse of alcohol by young people, 3 years after the UK government had introduced the option of 24-hour drinking. The British Medical Association (BMA) subsequently recommended that there should be a programme of research to examine the consequences of this change to our drinking culture. In 2008, it reported on current trends in alcohol misuse (BMA Board of Science, 2008). An appendix to that report summarises the different alcohol control strategies pursued by the governments of England, Wales, Scotland and Northern Ireland in the past few years. These are outlined in the document Safe. Sensible. Social. The Next Steps in the National Alcohol Strategy (HM Government, 2007).

In England, there is an emphasis on controlling alcohol misuse by the young through 'sharpened criminal justice for drunken behaviour', which contrasts sharply with the equivalent, more education-oriented strategies pursued by other regions in the UK. The distinction raises important questions about the evidence base for the relative effectiveness of persuasion and punitive action to curb substance misuse.

The UK ranks among the heaviest alcohol-consuming countries in Europe. Overall, the majority of the UK adult population drinks alcohol, but the prevalence varies considerably by ethnic group. While just $9 \%$ of White British people abstain, the equivalent proportions are $48 \%$ of people of Black African origin and over $90 \%$ among those of Pakistani and Bangladeshi origin. Cultural differences in alcohol consumption among the young are reflected in our choice of papers for this issue's theme.

To start, we have a fascinating report by doctors in Pakistan who studied attitudes to alcohol among medical students in Lahore. Nazish Imran and colleagues observed that medical students the world over are notorious for their liberal consumption of alcohol, so they conducted a local survey, which had an excellent response rate. They found surprisingly liberal attitudes to alcohol consumption among Pakistani students, but because social attitudes to drinking are in general very conservative, it was not possible to discover how many students themselves were users.

A second report on attitudes to alcohol among the young comes from Drs Nkire and Nwachukwu, in Ireland. They express concern that the average age of drink initiation in that country is just 13 years, and is falling. An amazing $25 \%$ of children claim to get drunk regularly. They discuss potential influences on this highly undesirable behaviour, and make some stark observations about the considerable gap between the aims of Irish government policy initiatives that are designed to curb alcohol misuse, and the vigour with which they have been implemented.

Finally, we have good news from Iceland. In the late 1990s there was a serious drink problem among adolescents in that country, a situation not dissimilar to the current experience of the UK. Inga Dora Sigfusdottir and colleagues outline the collaborative community-based approach that evolved to deal with the issue. We learn how 'joined up thinking' by governmental and non-governmental organisations allowed them to put in place novel strategies of primary prevention. Their approach was based upon published evidence and was underpinned by theories from social science. Key to the remarkable success of the programme was its broadbased community support, in particular the willingness of parents to take responsibility for, and to closely supervise, their children's social activities. Alcohol misuse among the young was halved in just 10 years. We should be listening.

\section{References}

BMA Board of Science (2008) Alcohol Misuse: Tackling the UK Epidemic. Available at http://www.bma.org.uk/images/Alcoholmisuse tcm41147192.pdf (accessed August 2010).

HM Government (2007) Safe. Sensible. Social. The Next Steps in the National Alcohol Strategy. Available at http://www.dh.gov.uk/ prod_consum_dh/groups/dh_digitalassets/@dh/@en/documents/ digitalasset/dh_075219.pdf (accessed August 2010). 